\title{
Isolated right ventricular dysfunction in systemic sclerosis: latent pulmonary hypertension?
}

\author{
S. Huez*\#, F. Roufosse ", J-L. Vachiéry*, A. Pavelescu*, G. Derumeaux ${ }^{+}$, \\ J-C. Wautrecht ${ }^{\S}$, E. Cogan ${ }^{\uparrow}$ and R. Naeije ${ }^{\#}$
}

ABSTRACT: Right ventricular function is frequently abnormal in patients with systemic sclerosis, but whether this is related to pulmonary vascular complications of the disease is unclear.

Standard echocardiography with tissue Doppler imaging was performed at rest and during exercise for the study of right ventricular function and pulmonary circulation in 25 consecutive systemic sclerosis patients and in 13 age-matched healthy controls.

When compared with the controls, the patients had no difference in systolic right ventricular pressure gradient, but a decreased pulmonary flow acceleration time, and increased right ventricular free wall thickness and end-diastolic dimensions. At the tricuspid annulus, the $E$ maximal velocity was decreased $\left(8.9 \pm 4\right.$ versus $\left.11.7 \pm 2.3 \mathrm{~cm} \cdot \mathrm{s}^{-1}\right)$ and the isovolumic relaxation time corrected to $R R$ interval was increased (6.5 \pm 2.9 versus $4.5 \pm 2.5 \%)$. The tissue Doppler imaging profile at the mitral annulus was similar in both groups. At exercise, 18 patients had a decreased maximum workload and cardiac output, no change in systolic right ventricular pressure gradient, but an increase in the slope of pulmonary artery pressure/flow relationships.

These results suggest that patients with systemic sclerosis may present with latent pulmonary hypertension as a likely cause of right ventricular diastolic dysfunction, as revealed by stress echocardiography and tissue Doppler imaging.

KEYWORDS: Echocardiography, heart failure, pulmonary hypertension, right ventricle, systemic sclerosis, tissue Doppler imaging

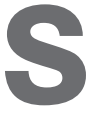
ystemic sclerosis is a generalised connective tissue disorder characterised by vascular lesions and extensive fibrosis of the skin and visceral organs, including the heart, kidneys and lungs. The hallmark of systemic sclerosis heart disease is myocardial fibrosis and ischaemia leading to progressive hypertrophy and both diastolic and systolic dysfunction [1] Systemic sclerosis is also frequently complicated by pulmonary hypertension (PH). An increase in pulmonary artery pressure has been reported in $5-50 \%$ of patients [2], and is associated with poor prognosis and identified as a cause of altered diastolic function of both right and left ventricles (RV and LV, respectively) [2-6].

Recently, a pulsed-tissue Doppler imaging (TDI) study showed that systemic sclerosis patients often present with a predominantly early-diastolic RV dysfunction in the presence of a normal systolic pulmonary artery pressure, as estimated from maximum velocity of tricuspid regurgitation [6]. This observation raised the question as to whether abnormal RV function in systemic sclerosis without $\mathrm{PH}$ could be related to the intrinsic effects of the disease or to associated latent pulmonary vasculopathy. The maximum velocity of tricuspid regurgitation, which is currently recommended in screening for $\mathrm{PH}$ programmes [2, 7], could indeed lack sufficient sensitivity and specificity for the detection of mild $\mathrm{PH}$ [8], and would not be able to predict daily activity exercise-related abnormal increases in pulmonary artery pressures [9]. Doppler echocardiography for the detection of $\mathrm{PH}$ could possibly be improved by analysis of pulmonary artery flow waves or estimations of pulmonary artery pressures at exercise [2].

Therefore, the current authors investigated pulmonary haemodynamics and RV and LV function at rest and during exercise using both standard echocardiography and TDI, in an unselected group of 25 consecutive patients with systemic sclerosis, most of whom had no $\mathrm{PH}$ at rest. Specifically, the hypothesis tested in the
AFFILIATIONS

Depts of ${ }^{*}$ Cardiology,

"Pathophysiology,

"Internal Medicine, and

${ }^{\S}$ Vascular diseases, Hôpital Erasme, Université Libre de Bruxelles,

Belgium.

+Laboratory of Echocardiography, Hospital Louis Pradel, Lyon, France.

CORRESPONDENCE

R. Naeije

Laboratory of Physiology

Erasme Campus

CP 604

Route de Lennik 808

B-1070 Brussels

Belgium

Fax: 3225554124

E-mail: rnaeije@ulb.ac.be

Received:

March 042007

Accepted after revision:

July 242007

SUPPORT STATEMENT

The study was supported by Grant No. 3.3.4551.05 from the Fonds de la Recherche Scientifique Médicale (Brussels, Belgium) and by the Foundation for Cardiac Surgery (Brussels, Belgium). S. Huez is a fellow of the Fonds National de la Recherche Scientifique.

STATEMENT OF INTEREST None declared. 
present study was that an exercise stress test and analysis of pulmonary flow waves, added to the measurement of the maximum velocity of tricuspid regurgitation at rest, would improve the detection of mild or latent $\mathrm{PH}$ in systemic sclerosis. The results confirm that altered cardiac function in systemic sclerosis is most often limited to the RV in diastole, and suggest that this may be related to latent $\mathrm{PH}$.

\section{PATIENTS AND METHODS Study population}

In total, 25 consecutive patients with systemic sclerosis (23 females and two males) referred for echocardiographic screening of $\mathrm{PH}$, and 13 healthy controls (11 females and two males) with the same mean \pm SD age $(56 \pm 12$ versus $54 \pm 12$ yrs; $p=0.7)$ and body surface area $\left(1.6 \pm 0.1\right.$ versus $\left.1.7 \pm 0.2 \mathrm{~m}^{2} ; \mathrm{p}=0.6\right)$ gave written informed consent to the study, which was approved by the Institutional Review Board (Hôpital Erasme, Brussels, Belgium).

The diagnosis of systemic sclerosis conformed to the criteria of the American Rheumatism Association [10]. Of the study patients, 10 had limited cutaneous systemic sclerosis, 13 had diffuse cutaneous systemic sclerosis and two had polymyositis/scleroderma overlapping syndrome.

\section{Functional evaluation}

Exercise capacity was measured by a self-paced unencouraged 6-min walk test in both patients [2] and controls. Heart rate and arterial oxygen saturation $\left(\mathrm{Sa}_{2} \mathrm{O}_{2}\right)$ were measured before and at the end of the test by pulse oximetry (Nellcor, Tyco Healthcare, Mechelen, Belgium). Lung function tests were performed in the patients in the same month as the echocardiography examination.

\section{Echocardiography}

Data acquisition

Echocardiography was performed with a Vivid 7 ultrasound system (General Electric Medical System, Milwaukee, WI, USA) equipped with a 3-MHz transducer and TDI technology. Pulsed-TDI recordings were acquired from an apical fourchamber view during a short end-expiration pause. PulsedTDI volume samples were recorded on the lateral side of the mitral annulus and on the free-wall side of the tricuspid annulus [11].

Exercise echocardiography was performed on a supine ergometer (Ergometrics 800; Ergoline, Bitz, Germany). The exercise table was tilted laterally by $20-30^{\circ}$ to the left. After obtaining Doppler echocardiography images at rest, exercise was started at an initial workload of $20 \mathrm{~W}$. Workload was increased by $20 \mathrm{~W}$ every $2 \mathrm{~min}$, and blood pressure and 12-lead electrocardiogram were recorded [12, 13].

\section{Data analysis and measurements}

A single observer performed the on-line and the off-line analyses. The off-line analyses were done in a blinded fashion. All measurements were made in triplicate and results are presented as means.

Aortic cardiac output was calculated from the velocity-time integral of the pulsed-TDI tracing in the LV outflow tract. Pulmonary artery pressure was estimated from the maximal velocity of the tricuspid regurgitant jet to calculate a systolic RV pressure gradient. PH was defined by a tricuspid regurgitant jet maximal velocity $\geqslant 2.8 \mathrm{~m} \cdot \mathrm{s}^{-1}$ (gradient= $30 \mathrm{mmHg}$ ) [7]. The Doppler velocity profile was recorded in the RV outflow tract to measure pulmonary acceleration time

TABLE 1 Conventional echocardiography measurements in patients with systemic sclerosis and control subjects

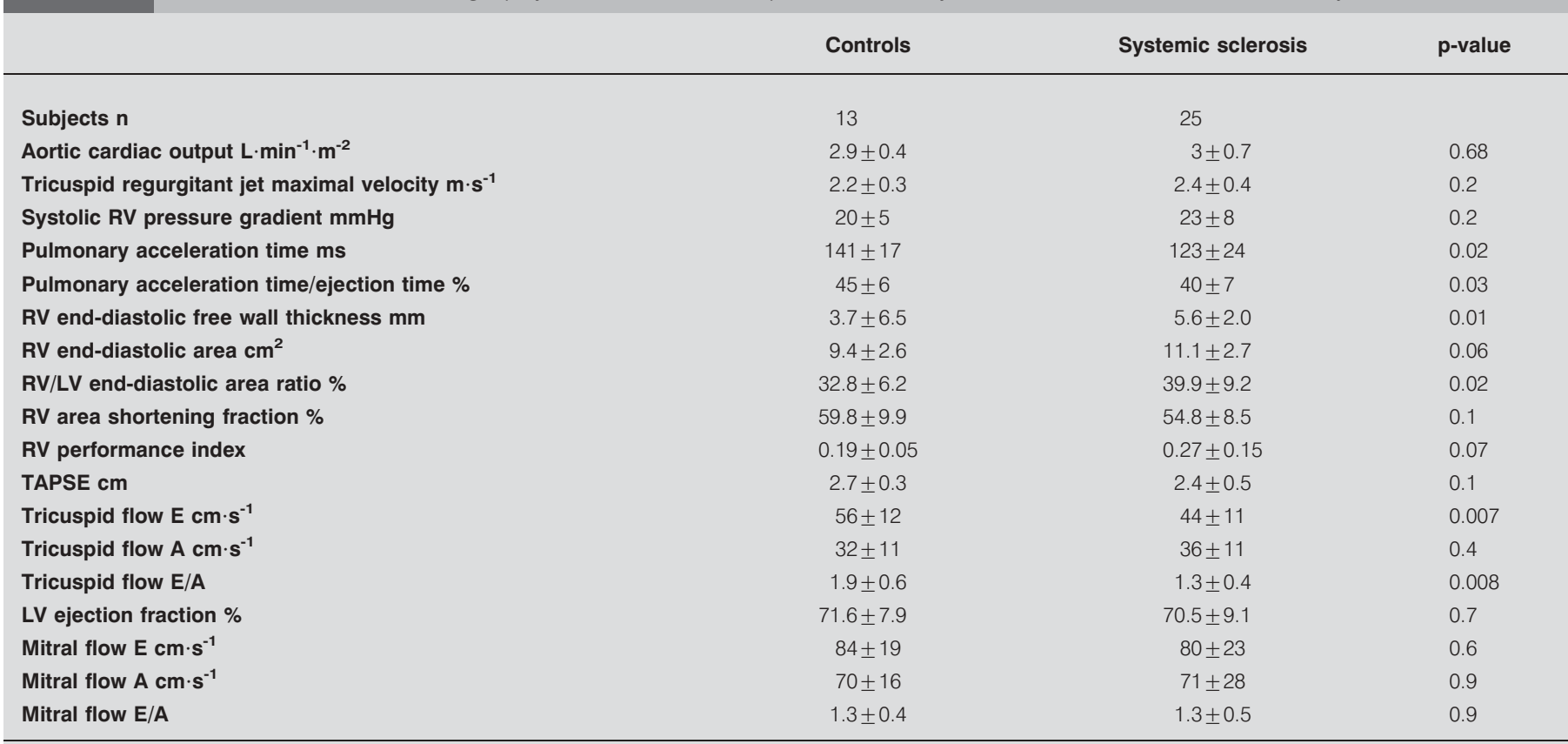

Data are presented as mean \pm SD, unless otherwise stated. RV: right ventricle; LV: left ventricle; TAPSE: tricuspid annular plane systolic excursion; E: early diastolic wave A: late diastolic wave. 


\begin{tabular}{|c|c|c|c|c|c|c|c|c|}
\hline TABL & $\begin{array}{l}\text { Invasi } \\
\text { cathe }\end{array}$ & $\begin{array}{l}\text { eeasurements ar } \\
\text { ation }\end{array}$ & inam & pulmonary vascl & resis & e $(P \vee R)$ in four $p$ & ts who u & went a right heart \\
\hline \multirow[t]{2}{*}{ Patient } & \multicolumn{2}{|c|}{$\bar{P}$ pa $\mathrm{mmHg}$} & \multicolumn{2}{|c|}{ PAOP $\mathrm{mmHg}$} & \multicolumn{2}{|c|}{ Cardiac output L. $\mathrm{min}^{-1}$} & \multicolumn{2}{|c|}{ Dynamic PVR $\mathrm{mmHg} \cdot \mathrm{L}^{-1} \cdot \mathrm{min}^{-1}$} \\
\hline & Rest & Maximal exercise & Rest & Maximal exercise & Rest & Maximal exercise & Invasive & Echocardiography \\
\hline A & 37 & & 8 & & 4.6 & & & \\
\hline C & 23 & 33 & 17 & 23 & 4.5 & 6.2 & 5 & 6 \\
\hline D & 27 & 44 & 13 & 14 & 4.1 & 5.2 & 17 & 16 \\
\hline
\end{tabular}

$\bar{P}$ pa: mean pulmonary artery pressure; PAOP: pulmonary arterial occlusion pressure.

and ejection time [14]. RV free wall thickness was measured by Mmode in a parasternal axis. To calculate LV ejection fraction, end-systolic and end-diastolic LV areas and volumes were measured from an apical four-chamber view. Systolic and diastolic RV function was assessed by the RV area shortening fraction, the RV on LV end-diastolic area ratio [15] and the tricuspid annular plane systolic excursion (TAPSE) [16], as well as by the RV myocardial performance index defined by:

( $\mathrm{RV}$ isovolumic contraction time+RV isovolumic relaxation time)/RV ejection time

and calculated as the ratio [17]:

(tricuspid closing to opening time-RV ejection time)/RV ejection time

Mitral and tricuspid Doppler inflow patterns were obtained from an apical four-chamber view to measure early (E) and late (A) diastolic wave peak velocities.

From pulsed-TDI traces, mitral and tricuspid annuli peaks isovolumic contraction relocities (ICV) at, systolic ejection (S), E and A were measured. The isovolumic contraction acceleration
(ICA) was calculated as the difference between baseline and peak velocity divided by their time interval [18]. The isovolumic relaxation time (IRT) was measured as the time between the end of $S$ wave and the beginning of $E$ wave, and "time to $E$ " as the time between the onset of the QRS complex and the onset of $\mathrm{E}$ wave. To minimise the influence of the heart rate, all times were corrected to the RR interval between two QRS complexes [11].

During exercise echocardiography, the aortic cardiac output and the systolic RV pressure gradient were recorded at each step [12, 13]. The regression equation between systolic RV pressure gradient and cardiac output was calculated for each subject, and the slope of this relationship was considered as the dynamic pulmonary vascular resistance (PVR) [19, 20].

\section{Statistical analysis}

Results are expressed as mean $\pm \mathrm{SD}$. Comparisons between patients and controls were made with unpaired t-tests on the main end-points and the exploratory secondary end-points, without correction for multiple comparisons. Linear regressions were calculated using the least squares method on

TABLE 3 Pulsed-tissue Doppler imaging measurements in patients with systemic sclerosis ${ }^{\#}$ and control subjects ${ }^{*}$

\begin{tabular}{|c|c|c|c|c|c|c|}
\hline & \multicolumn{3}{|c|}{ Tricuspid annulus } & \multicolumn{3}{|c|}{ Mitral annulus } \\
\hline & Controls & Systemic sclerosis & $\mathrm{p}$-value & Controls & Systemic sclerosis & $\mathrm{p}$-value \\
\hline RR ms & $952 \pm 181$ & $849 \pm 147$ & 0.06 & $928 \pm 164$ & $839 \pm 143$ & 0.1 \\
\hline $\mathrm{ICV} \mathrm{cm} \cdot \mathrm{s}^{-1}$ & $10 \pm 3$ & $11 \pm 3$ & 0.5 & $6 \pm 1$ & $6 \pm 2$ & 0.7 \\
\hline ICA $\mathrm{cm} \cdot \mathrm{s}^{-2}$ & $0.4 \pm 0.1$ & $0.3 \pm 0.1$ & 0.5 & $0.3 \pm 0.1$ & $0.3 \pm 0.1$ & 0.7 \\
\hline$A \mathrm{~cm} \cdot \mathrm{s}^{-1}$ & $14 \pm 3$ & $15 \pm 5$ & 0.5 & $10 \pm 3$ & $11 \pm 4$ & 0.3 \\
\hline$E / A$ & $0.9 \pm 0.3$ & $0.7 \pm 0.4$ & 0.2 & $1.3 \pm 0.6$ & $1.1 \pm 0.5$ & 0.3 \\
\hline IRT ms & $41 \pm 15$ & $53 \pm 20$ & 0.04 & $74 \pm 29$ & $81 \pm 21$ & 0.4 \\
\hline IRT/RR \% & $4.5 \pm 2.5$ & $6.5 \pm 2.9$ & 0.03 & $8 \pm 3.2$ & $9.8 \pm 2.5$ & 0.07 \\
\hline Time to E ms & $424 \pm 36$ & $431 \pm 35$ & 0.6 & $451 \pm 42$ & $449 \pm 39$ & 0.9 \\
\hline Time to E/RR \% & $46 \pm 9$ & $52 \pm 8$ & 0.03 & $46 \pm 13$ & $55 \pm 8$ & 0.01 \\
\hline
\end{tabular}

Data are presented as mean $\pm S D$, unless otherwise stated. IVC: isovolumic contraction velocity; ICA: isovolumic contraction wave acceleration; S: systolic ejection; $\mathrm{E}$ : early diastolic wave; A: late diastolic wave; IRT: isovolumic relaxation times; time to E: time from the onset of the QRS complex on the echocardiogram trace and onset of $E . \#: n=25 ; ": n=13$. 

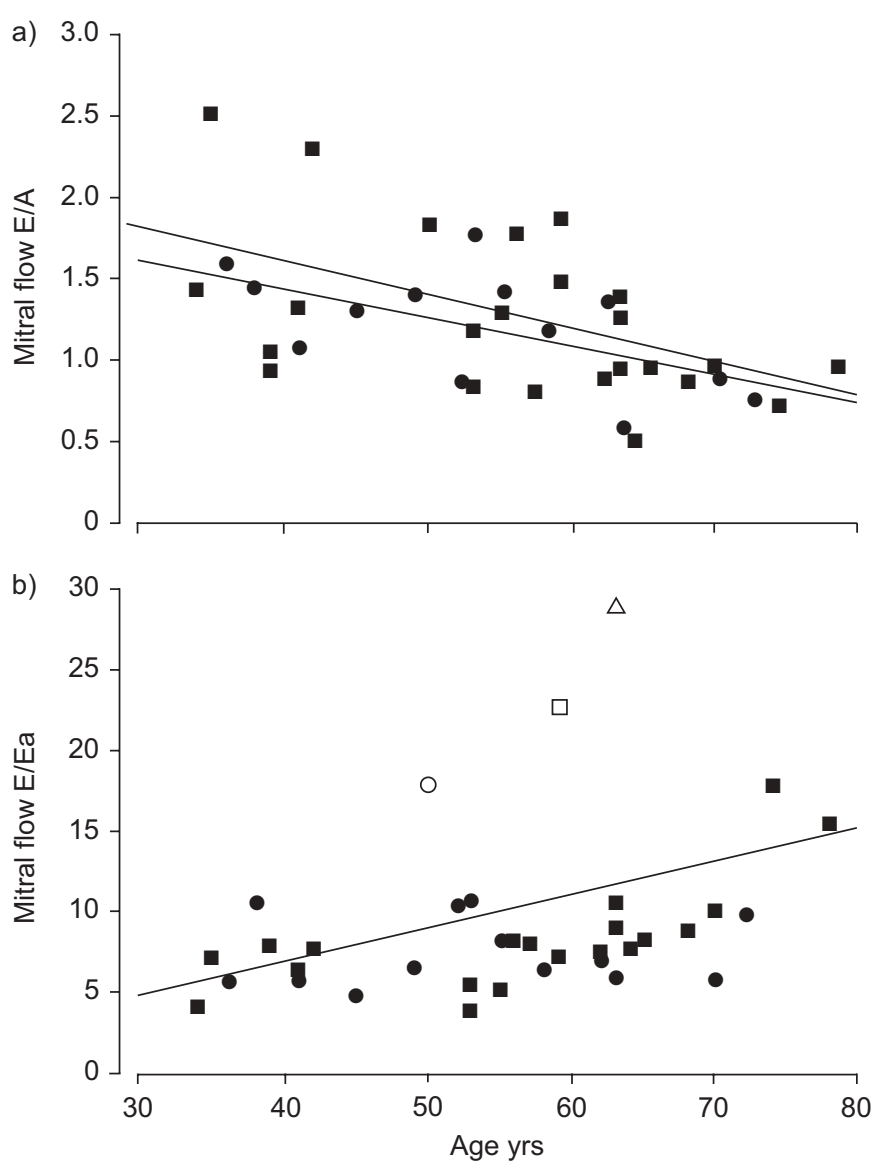

FIGURE 1. Relationship between age and a) mitral flow early diastolic wave (E)/ late diastolic wave (A), and b) mitral flow $E /$ mitral annulus $E(E a)$ in systemic sclerosis patients and controls. Mitral flow E/mitral Ea versus age was abnormal in three patients. $\square$ : systemic sclerosis; $\bullet$ : controls; $\square$ : patient $B ; \triangle$ : patient $C$; $O$ : patient $E$.

pressure and flow coordinates from each individual patient and control subject. Linear correlations between pulsed-TDI indices and exercise echocardiography variables were also calculated. A p-value $<0.05$ was considered significant [21].

\section{RESULTS}

\section{Functional evaluation}

In total, six patients complained of exertional dyspnoea for more than ordinary efforts. Four of them had a right heart catheterisation. The other two declined the exercise test due to fatigue and respiratory discomfort. The 6-min walk distance was $471 \pm 123 \mathrm{~m}$ with a Borg scale score of $5 \pm 2$ in the patients, and $624 \pm 103 \mathrm{~m}$ with a Borg scale score of $2 \pm 1$ in the controls $(\mathrm{p}<0.001)$. Heart rate $\left(84 \pm 14\right.$ versus $83 \pm 13$ beats $\left.\cdot \mathrm{min}^{-1} ; \mathrm{p}=0.8\right)$ and $\mathrm{Sa}_{1} \mathrm{O}_{2}(99 \pm 1$ versus $99 \pm 2 \% ; \mathrm{p}=0.9)$ at rest were similar in both groups. At the end of the 6-min walk test, $\mathrm{Sa}_{2} \mathrm{O}_{2}$ was similar in both groups $(97 \pm 5$ versus $98 \pm 2 \%$; $p=0.3)$; however, the maximum heart rate was lower in the patients $(112 \pm 22$ versus $130 \pm 20$ beats $\cdot \mathrm{min}^{-1} ; \mathrm{p}=0.02$ ).

\section{Conventional echocardiography}

Heart rate $\left(76 \pm 11\right.$ versus $70 \pm 12$ beats $\left.\cdot \mathrm{min}^{-1} ; \mathrm{p}=0.1\right)$, mean systemic arterial pressure $(91 \pm 11$ versus $92 \pm 9 \mathrm{mmHg}$; $\mathrm{p}=0.69$ ) and cardiac output (table 1 ) were similar in both groups. Three patients had a maximum velocity of tricuspid regurgitation of $>2.8 \mathrm{~m} \cdot \mathrm{s}^{-1}$. These patients underwent a right heart catheterisation, which allowed the identification of pulmonary arterial hypertension in one patient (patient $\mathrm{A}$; table 2) and post-capillary $\mathrm{PH}$ was revealed at exercise in the two other patients (patients B and C; table 2).

When compared with the controls, the patient population group as a whole had a normal systolic RV pressure gradient, RV area shortening fraction and TAPSE, but presented a decreased pulmonary acceleration time, a slightly increased RV free wall thickness and RV/LV end-diastolic area. The RV performance index remained within normal limits, but may have shown a tendency to increase $(p=0.07)$, and the tricuspid flow $\mathrm{E}$ and $\mathrm{E} / \mathrm{A}$ ratio were decreased, suggesting RV diastolic dysfunction. The patients and the controls were otherwise similar for LV ejection fraction and mitral inflow pattern.

\section{Annular planes pulsed-TDI}

As shown in table 3, the patients and the controls had comparable indices of RV and LV systolic function (ICV, ICA and $\mathrm{S}$ ). However, in the patients, tricuspid annulus $\mathrm{E}$ was decreased and IRT, IRT/RR and time to E/RR were increased. At the mitral annulus, E and IRT/RR showed a similar trend, but the changes did not reach a statistical level of significance $(p=0.06)$ and the time to E/RR was significantly increased. As

\section{TABLE 4 Exercise measurements in patients with systemic sclerosis and control subjects}

Controls

Subjects $n$

Maximal mean systemic arterial pressure $\mathrm{mmHg}$

Maximal workload W

Maximal heart rate beats $\cdot \min ^{-1}$

Maximal aortic cardiac output L. $\mathrm{min}^{-1}$

Maximal systolic RV pressure gradient $\mathrm{mmHg}$

Dynamic PVR $\mathrm{mmHg} \cdot \mathrm{L}^{-1} \cdot \mathrm{min}^{-1}$

12

12

$118 \pm 14$

$106 \pm 30$

$141 \pm 12$

$11.6 \pm 3.1$

$40 \pm 9$

$5.5 \pm 3.4$
Systemic sclerosis

18

$119 \pm 14$

$71 \pm 26$

$126 \pm 19$

$8.7 \pm 2$

$39 \pm 12$

$2.9 \pm 1.1$ $p$-value

0.8

0.002

0.04

0.007

0.7

0.02

Data are presented as mean $\pm \mathrm{SD}$, unless otherwise stated. RV: right ventricle; PVR: pulmonary vascular resistance. 

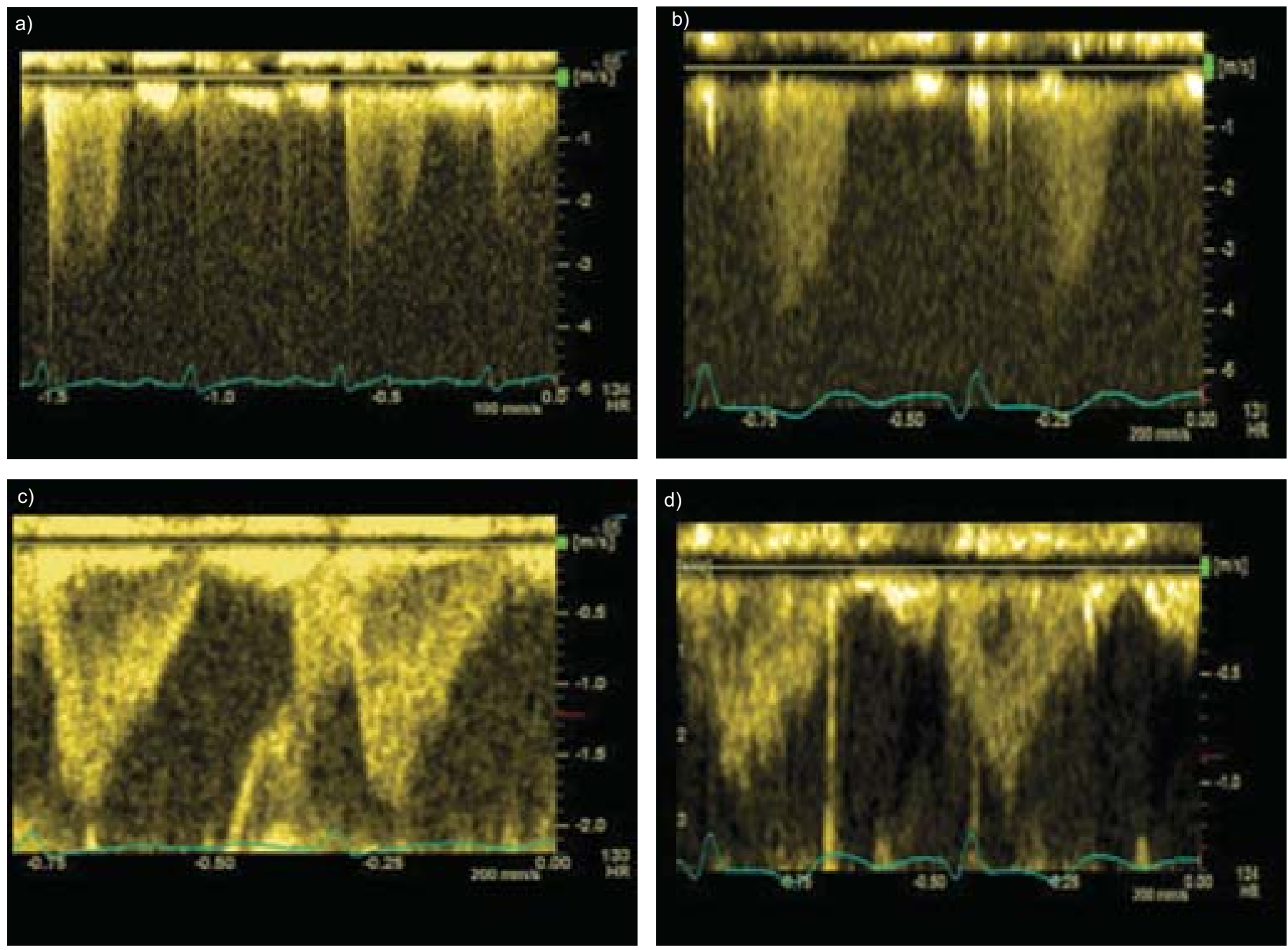

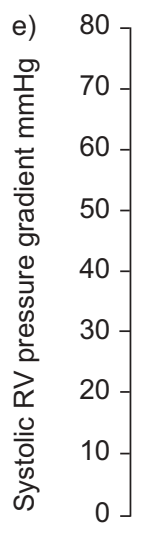

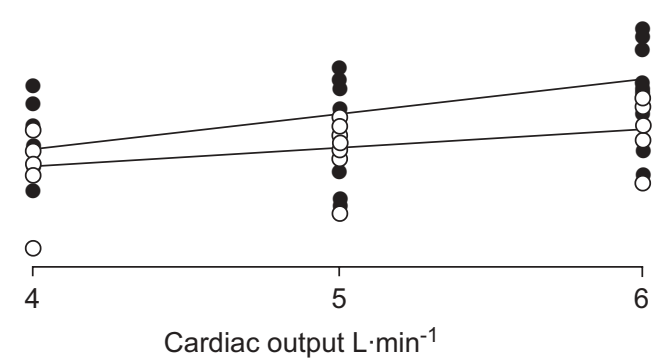

FIGURE 2. a-d) Tricuspid regurgitant and aortic flow recorded at exercise in a normal subject $(a, b)$ and in a systemic sclerosis patient with exercise pulmonary arterial hypertension (c, d). e) Mean regression equation lines between systolic right ventricle (RV) pressure gradient and cardiac output during exercise in patients with systemic sclerosis $(\bullet)$ and controls subjects $(\bigcirc)$. The pressures were recalculated at 4,5 and $6 \mathrm{~L} \cdot \mathrm{min}^{-1}$ from individual linear regressions. The slope of the relationship, defining dynamic pulmonary vascular resistance, was increased in the patients compared with the controls. $p=0.02 ; y=4.59 x-4.98$.

shown in figure 1, the relationship between mitral flow E and age did not differ in the patients and controls, but the relationship between mitral flow $\mathrm{E} /$ mitral annulus $\mathrm{E}$ ratio and index of left atrial pressure was abnormal in three patients. Two of them were patients B and C (table 2) who had exerciseinduced $\mathrm{PH}$ with diastolic dysfunction, as indicated by 

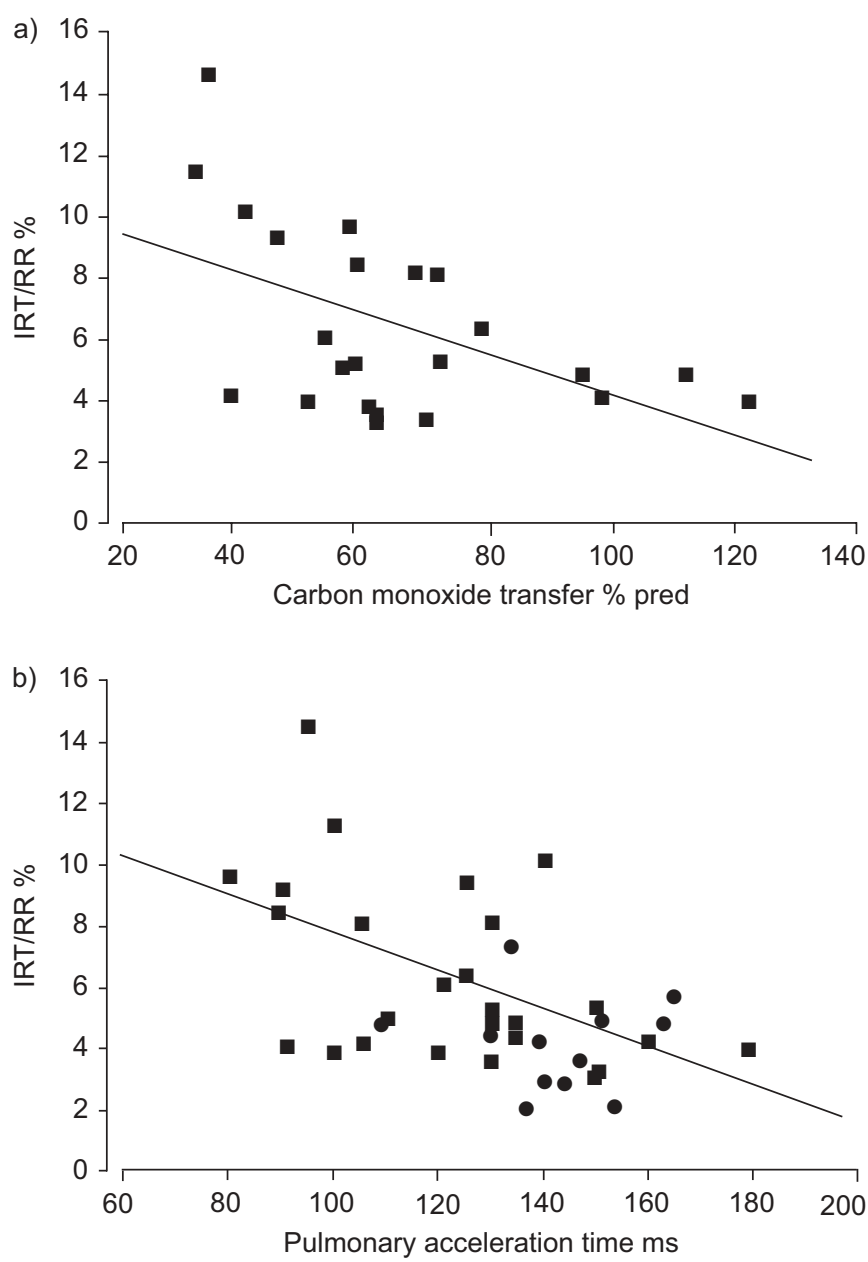

FIGURE 3. Linear correlation between tricuspid annulus tissue Doppler imaging, early diastolic indices isovolumic relaxation time (IRT)/RR and a) carbon monoxide transfer and b) pulmonary acceleration time of arterial oxygen saturation, in patients with systemic sclerosis ( $)$ and in controls

abnormally high resting and/or exercise pulmonary artery occlusion pressure. The third patient had a moderate LV hypertrophy.

\section{Exercise echocardiography}

The patient with confirmed pulmonary arterial hypertension at rest (patient A) was not proposed for exercise testing; one patient had ascendant aortic aneurysm contraindicating exercise and three patients could not perform the test due to chronic hip pain $(n=1)$ and invalidating dyspnoea and fatigue $(n=2)$. Two patients were excluded due to insufficient acoustic quality. Thus 18 patients underwent an exercise-stress echocardiography.

The patients presented with a decrease in maximal workload, heart rate and cardiac output, but no differences in RV pressure gradient and mean systemic artery pressure (table 4). The individual correlation coefficient of the relationship between systolic RV pressure gradient and cardiac output was $>0.90$ in all the subjects, except for one control subject who was excluded from the exercise analysis. The mean dynamic
PVR was increased two-fold in the patients compared with the controls (figure 2).

In one patient with a very abnormal pulmonary pressure response to exercise (maximal systolic RV pressure gradient $70 \mathrm{mmHg}$ ), a right heart catheterisation confirmed the presence of mild pulmonary arterial hypertension (mean pulmonary artery pressure $27 \mathrm{mmHg}$ ) worsened by exercise (patient D; table 2).

\section{Pulmonary function tests}

The pulmonary function tests in the patients showed a carbon monoxide transfer of $65 \pm 24 \%$ predicted and a total lung capacity of $96 \pm 23 \%$ pred. Only three patients had a total lung capacity $<70 \%$ pred. Of these, two had mild lung fibrosis on computed tomography examination of the chest and no increased maximum velocity of tricuspid regurgitation at rest, but they did not perform an exercise test. The third was a 57-yr-old female with exerciseinduced $\mathrm{PH}$ and LV diastolic dysfunction (patient B; table 2).

Relationship between RV function and functional evaluation No correlation was found between TDI indices of RV function and the 6-min walk distance. However, the tricuspid annulus IRT/RR was correlated to the $S_{a}, \mathrm{O}_{2}$ measured at the end of the 6-min walk test. Two patients had an $\mathrm{Sa}_{1} \mathrm{O}_{2}<90 \%$ at the end of the test and were the patients with pulmonary arterial hypertension at rest and at exercise $\left(\mathrm{Sa}_{1} \mathrm{O}_{2} \quad 89\right.$ and $77 \%$, respectively). The tricuspid annulus IRT/RR was correlated to the carbon monoxide transfer (fig. 3).

\section{Relationship between RV function and indices of the pulmonary circulation}

Tricuspid annulus E and IRT/RR were correlated to systolic RV pressure gradient and pulmonary acceleration time measured at rest (fig. 3), and IRT/RR was correlated to the dynamic PVR at exercise (fig. 4). Typical tricuspid annulus TDI tracings in a normal subject and in the patient suffering from exercise pulmonary arterial hypertension are shown in figure 4 .

\section{DISCUSSION}

The present results confirm that systemic sclerosis patients frequently present with an altered diastolic function of the RV, and suggest that this is possibly related to latent $\mathrm{PH}$.

There has been interest in recent years in the use of pulsed-TDI for the study of RV function. Compared with standard Doppler echocardiography approaches, TDI allows for a high recovery rate of sufficient quality signals [11], direct measurements of long axis myocardial tissue velocity changes that are most relevant to RV performance [22, 23], and relative pre-load independence $[18,24]$. Pulsed-TDI has been reported to be more sensitive than conventional echocardiography for the detection of latent LV function alterations, in particular LV diastolic function and noninvasive estimation of end-diastolic pressure by the measurement of mitral flow/annulus $\mathrm{E}$ waves $[18,24,25]$.

In the present study, pulsed-TDI measurements showed an isolated or predominantly RV diastolic dysfunction in the presence of normal pulmonary artery pressures. This could be explained by a preferential RV sensitivity to the effects of systemic disease. However, there is no previous report of asymmetric intrinsic cardiomyopathy in systemic sclerosis [1] 

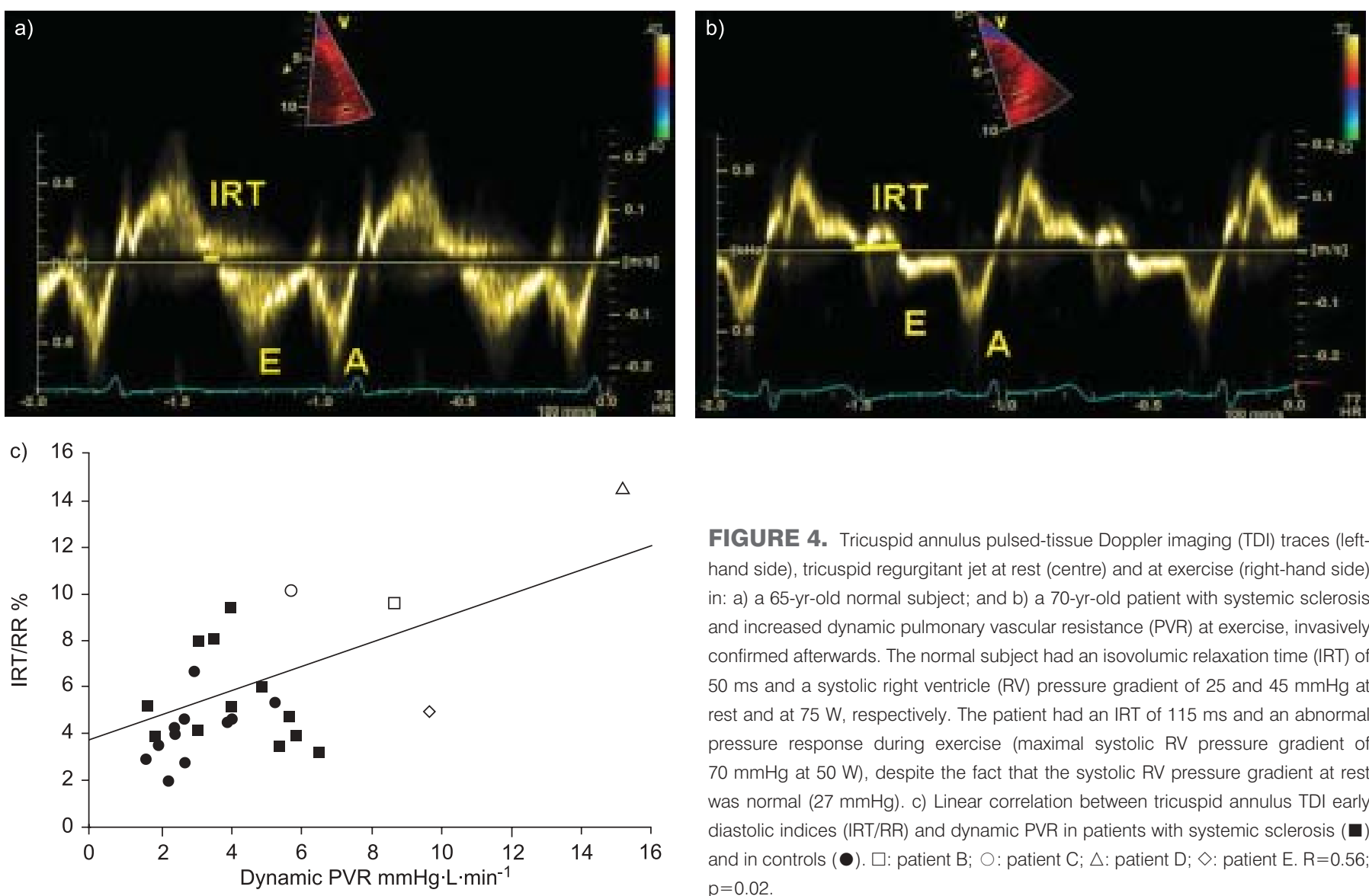

FIGURE 4. Tricuspid annulus pulsed-tissue Doppler imaging (TDI) traces (lefthand side), tricuspid regurgitant jet at rest (centre) and at exercise (right-hand side) in: a) a 65-yr-old normal subject; and b) a 70-yr-old patient with systemic sclerosis and increased dynamic pulmonary vascular resistance (PVR) at exercise, invasively confirmed afterwards. The normal subject had an isovolumic relaxation time (IRT) of $50 \mathrm{~ms}$ and a systolic right ventricle (RV) pressure gradient of 25 and $45 \mathrm{mmHg}$ at rest and at $75 \mathrm{~W}$, respectively. The patient had an IRT of $115 \mathrm{~ms}$ and an abnormal pressure response during exercise (maximal systolic RV pressure gradient of $70 \mathrm{mmHg}$ at $50 \mathrm{~W}$ ), despite the fact that the systolic RV pressure gradient at rest was normal $(27 \mathrm{mmHg})$. c) Linear correlation between tricuspid annulus TDI early diastolic indices (IRT/RR) and dynamic PVR in patients with systemic sclerosis ( and in controls $(\bullet)$. $\square$ : patient $B$; $\bigcirc$ : patient $C$; $\triangle$ : patient $D$; $\diamond$ : patient $E$. R $=0.56$; $p=0.02$.

A more likely explanation would relate altered RV diastolic function to pulmonary haemodynamics. The IRT/RR in the present study patients was correlated to the systolic RV pressure gradient, even though this measurement was not significantly different from the controls. This result is in keeping with previous studies that used simultaneous phonocardiography and Doppler echocardiography to establish an inverse relationship between RV IRT and systolic pulmonary artery pressures [26].

The estimation of systolic RV pressure gradient from the maximum velocity of the tricuspid regurgitation has been recommended for the purpose of noninvasive screening for $\mathrm{PH}$ in populations at risk [2, 7]. While this strategy has indeed entered clinical practice, pulmonary artery pressures can also be estimated from the acceleration time of pulmonary flow velocity $[2,14]$. In the study patients, pulmonary acceleration time, although on average within the limits of normal, was decreased and inversely correlated to the tricuspid annulus E and IRT/RR. This was also recently found in a study on a similar systemic sclerosis patient population [6]. Pulmonary flow waves in PH typically show a decreased acceleration time and late- or mid-systolic deceleration [14]. These changes have been explained by increased pulmonary arterial elastance and wave reflection [14, 27]. In fact, pulmonary acceleration time decreases with increasing characteristic impedance, which is a major determinant of right ventricular hydraulic load [27, 28]. Therefore, decreased pulmonary acceleration time in the study

patients would be a reflection of early remodelling of the pulmonary vasculature.

While Doppler echocardiography remains an indispensable tool for the detection of $\mathrm{PH}$ in populations at risk, it remains unsatisfactory due to a lack of sensitivity and specificity, particularly for the detection of mild $\mathrm{PH}[2,7,8]$. In addition, resting measurements may not reflect exercise-induced $\mathrm{PH}$, which can be prominent during daily activities in systemic sclerosis patients. [9]. A Raynauds phenomenon of the pulmonary vasculature has been proposed as a potential mechanism in labile PH associated with systemic sclerosis [29], but a pulmonary pressor response has not been reported in these patients during central cold tests or by hand immersion cold challenges [30]. Exercise Doppler echocardiography has been used to reveal abnormal pulmonary vascular response in high-altitude pulmonary oedema-susceptible subjects or in asymptomatic carriers of the primary $\mathrm{PH}$ gene $[12,13]$. In the present study, resting and exercise-stress echocardiography were combined, and thereby detected four abnormal responses in the 25 consecutive systemic sclerosis patients. Right heart catheterisation confirmed pulmonary arterial hypertension in two of these patients. This result is in accordance with the recently reported prevalence of $7.85 \%$ of pulmonary arterial hypertension associated with systemic sclerosis in France [31]. It is of interest to note that one of these two patients had normal systolic RV pressure gradient at rest but a very abnormal pressure response to exercise (dynamic PVR 
$\left.16 \mathrm{mmHg} \cdot \mathrm{L}^{-1} \cdot \mathrm{min}^{-1}\right)$. The diagnosis of pulmonary arterial hypertension would have been missed in this patient with the conventional echocardiography screening at rest.

In the current study, the patients presented with a decreased exercise capacity and a decreased maximum workload, heart rate, cardiac output and 6-min walk distance. Exercise capacity in systemic sclerosis may be decreased due to skeletal muscle involvement and deconditioning [32], or RV flow output limitation in the presence of increased PVR [33, 34]. In the current study, the patients achieved the same systolic RV pressure gradient at maximum exercise as the controls, in spite of a lower maximum cardiac output, clearly indicating an increased PVR. This was confirmed by an increased slope of multipoint systolic pulmonary artery pressure-flow relationships, or dynamic PVR. Pulmonary artery pressure/flow plots may be more sensitive than isolated PVR determinations to detect subtle changes in the functional state of the pulmonary circulation $[19,20,35]$. In the present study, dynamic PVR was increased two-fold in the patients compared with the controls, despite the fact that none of these patients had $\mathrm{PH}$ at rest. Altogether, the present data are suggestive of significant changes in the pulmonary circulation with impact on RV function in systemic sclerosis patients with a normal RV systolic pressure gradient at rest.

The mechanisms of pulmonary vasculopathy in systemic sclerosis are complex. The study patients had normal lung volumes, which rules out a significant contribution of interstitial fibrosis. Resting oxygen saturation was normal. There was an exercise-associated decrease in oxygen saturation, but this was not severe enough to be associated with hypoxic pulmonary vasoconstriction, except possibly for two of the patients with end of exercise $\mathrm{Sa}_{1} \mathrm{O}_{2}<90 \%$. The carbon monoxide transfer was decreased, and this has shown to be predictive of subsequent pulmonary arterial hypertension in patients with the CREST (Calcinosis, Raynaud, Esophagus, Sclerdoctyly, Telangiectasis) syndrome [36]. Diastolic dysfunction can also lead to an abnormal increase in pulmonary artery pressures, due to upstream transmission of associated increase in LV diastolic pressure. The three patients with LV diastolic dysfunction (one had LV hypertrophy at the echocardiography and two had diagnosis confirmed by right heart catheterisation) had dynamic PVR values between $5.6-10 \mathrm{mmHg} \cdot \mathrm{L}^{-1} \cdot \mathrm{min}^{-1}$.

In conclusion, patients with systemic sclerosis present with pulsed-tissue Doppler imaging indices indicative of predominant diastolic right ventricle dysfunction. The current authors speculate that this is related to latent pulmonary hypertension, revealed by an exercise stress test and pulmonary artery flow wave analysis.

\section{REFERENCES}

1 Follansbee WP, Curtiss EI, Medsger TA Jr, et al, Physiologic abnormalities of cardiac function in progressive systemic sclerosis with diffuse scleroderma. $N$ Engl J Med 1984; 310: 142-148.

2 McGoon M, Gutterman D, Steen V, et al. Screening, early detection, and diagnosis of pulmonary arterial hypertension: ACCP evidence-based clinical practice guidelines. Chest 2004; 126: Suppl. 1, 14S-34S.
3 Denton C, Black C. Pulmonary hypertension in systemic sclerosis. Rheum Dis Clin North Am 2003; 29: 335-349.

4 Giunta A, Tirri E, Maione S, et al. Right ventricular diastolic abnormalities in systemic sclerosis. Relation to left ventricular involvement and pulmonary hypertension. Ann Rheum Dis 2000; 59: 94-98.

5 Candell-Riera J, Armadans-Gil L, Simeón CP, et al. Comprehensive noninvasive assessment of cardiac involvement in limited systemic sclerosis. Arthritis Rheum 1996; 39: 1138-1145.

6 Lindqvist P, Caidahl K, Neuman-Andersen G, et al. Disturbed right ventricular function in patients with systemic sclerosis: a Doppler tissue imaging study. Chest 2005; 128: 755-763.

7 Barst R, McGoon M, Torbicki A, et al. Diagnosis and differential assessment of pulmonary arterial hypertension. J Am Coll Cardiol 2004; 43: Suppl. 12, 40S-47S.

8 Mukerjee D, St George D, Knight C, et al. Echocardiography and pulmonary function as screening tests for pulmonary arterial hypertension in systemic sclerosis. Rheumatology (Oxford) 2004; 43: 461-466.

9 Raeside DA, Chalmers G, Clelland J, Madhok R, Peacock AJ. Pulmonary artery pressure variation in patients with connective tissue disease: 24 hour ambulatory pulmonary artery pressure monitoring. Thorax 1998; 53: 857-862.

10 Subcommittee for scleroderma criteria of the American Rheumatism Association Diagnostic and Therapeutic Criteria Committee. Preliminary criteria for the classification of systemic sclerosis (scleroderma). Arthritis Rheum 1980; 23: 581-590.

11 Huez S, Retailleau K, Unger $P$, et al. Right and left ventricular adaptation to hypoxia: a tissue Doppler imaging study. Am J Physiol Heart Circ Physiol 2005; 289: H1391-H1398.

12 Grunig E, Mereles D, Hildebrandt W, et al. Stress Doppler echocardiography for identification of susceptibility to high altitude pulmonary edema. J Am Coll Cardiol 2000; 35: 980-987.

13 Grunig E, Janssen B, Mereles D, et al. Abnormal pulmonary artery pressure response in asymptomatic carriers of primary pulmonary hypertension gene. Circulation 2000; 102: 1145-1150.

14 Kitabatake $\mathrm{A}$, Inoue $\mathrm{M}$, Asao $\mathrm{M}$, et al. Noninvasive evaluation of pulmonary hypertension by a pulsed Doppler technique. Circulation 1983; 68: 302-309.

15 Tei C, Dujardin KS, Hodge DO, et al. Doppler echocardiographic index for assessment of global right ventricular function. J Am Soc Echocardiogr 1996; 9: 838-847.

16 Galié N, Hinderlinter A, Torbicki A, et al. Effects of the oral endothelin-receptor antagonist bosentan on echocardiographic and Doppler measures in patients with pulmonary arterial hypertension. J Am Coll Cardiol 2003; 41: 1380-1386.

17 Ghio S, Recusani F, Klersy C, et al. Prognostic usefulness of tricuspid annular planes systolic excursion in patients with congestive heart failure secondary to idiopathic or ischemic dilated cardiomyopathy. Am J Cardiol 2000; 85: 837-842.

18 Vogel M, Schmidt MR, Kristiansen SB, et al. Validation of myocardial acceleration during isovolumic contraction as a 
novel noninvasive index of right ventricular contractility: comparison with ventricular pressure-volume relations in an animal model. Circulation 2002; 105: 1693-1699.

19 Janicki J, Weber KT, Likoff MJ, Fishman AP. The pressureflow response of the pulmonary circulation in patients with heart failure and pulmonary vascular disease. Circulation 1985; 72: 1270-1278.

20 Abdelkafi S, Melot C, Vachiéry JL, Brimioulle S, Naeije R. Partitioning of pulmonary vascular resistance in primary pulmonary hypertension. J Am Coll Cardiol 1998; 31: 1372-1376.

21 Winer BJ, Brown DR, Michels KM, eds. Statistical Principles in Experimental Design. 3rd Edn. New York, McGraw-Hill, 1991; pp. 220-283.

22 Armour JA, Pace JB, Randall WC. Interrelationship of architecture and function of the right ventricle. Am J Physiol 1970; 218: 174-179.

23 Leather HA, Ama' R, Missant C, Rex S, Rademakers FE, Wouters PF. Longitudinal but not circumferential deformation reflects global contractile function in the right ventricle with open pericardium. Am J Physiol Heart Circ Physiol 2006; 290: H2369-H2375.

24 Nagueh SF, Middleton KJ, Kopelen HA, Zoghbi WA, Quiňones MA. Doppler tissue imaging: a noninvasive technique for evaluation of left ventricular relaxation and estimation of filling pressures. J Am Coll Cardiol 1997; 30: 1527-1533.

25 Nagueh SF, Bachinski LL, Meyer D, et al. Tissue Doppler imaging consistently detects myocardial abnormalitites in patients with hypertrophic cardiomyopathy and provides a novel means for an early diagnosis before and independently of hypertrophy. Circulation 2001; 104: 128-130.

26 Hatle L. Non-invasive methods of measuring pulmonary artery pressure and flow velocity. In: Chazov EI, Smirnov VN, Oganov RG, eds. Cardiology: An International Perspective. New York, Plenum Press, 1984; pp. 783-790.

27 Furuno Y, Nagamoto Y, Fujita M, Kaku T, Sakurai S, Kuroiwa A. Reflection as a cause of mid-systolic deceleration of pulmonary flow wave in dogs with acute pulmonary hypertension: comparison of pulmonary artery constriction with pulmonary embolisation. Cardiovasc Res 1991; 25: 118-124.

28 Laskey WK, Ferrari VA, Palevsky HI, Kussmaul WG. Pulmonary artery hemodynamics in primary pulmonary hypertension. J Am Coll Cardiol 1993; 21: 406-412.

29 Ohar JM, Robichaud AM, Fowler AA, Glauser FL. Increased pulmonary artery pressure in association with Raynaud's phenomenon. Am J Med 1986; 81: 361-362.

30 Mukerjee D, Yap LB, Ong V, et al. The myth of pulmonary Raynaud's phenomenon: the contribution of pulmonary arterial vasospasm in patients with systemic sclerosis related pulmonary arterial hypertension. Ann Rheum Dis 2004; 63: 1627-1631.

31 Hachulla E, Gressin V, Guillevin L, et al. Early detection of pulmonary arterial hypertension in systemic sclerosis. Arthritis Rheumatism 2005; 52: 3792-3800.

32 Ringel RA, Brick JE, Brick JF, Gutmann L, Riggs JE. Muscle involvement in the scleroderma syndromes. Arch Intern Med 1990; 150: 2550-2552.

33 Morelli S, Ferrante L, Sgressia A, et al. Pulmonary hypertension is associated with impaired exercise performance in patients with systemic sclerosis. Scand J Rheumatol 2000; 29: 236-242.

34 Winslow TM, Ossipov M, Redberg RF, Fazio GP, Schiller NB. Exercise capacity and hemodynamics in systemic lupus erythematosis: a Doppler exercise study. Am Heart J 1993; 126: 410-414.

35 Castelain V, Chemla D, Humbert M, et al. Pulmonary artery pressure-flow relations after prostacyclin in primary pulmonary hypertension. Am J Respir Crit Care Med 2002; 165: 338-340.

36 Steen V, Medsger TA. Predictors of isolated pulmonary hypertension in patients with systemic sclerosis and limited cutaneous involvement. Arthritis Rheum 2003; 48: 516-522. 